\title{
Dual-frequency Dual-sense Circularly-polarized Slot Antenna Fed by Microstrip Line
}

\author{
Xiulong Bao \\ Technological University Dublin, xiulong.bao@tudublin.ie \\ Max Ammann \\ Technological University Dublin, max.ammann@tudublin.ie
}

Follow this and additional works at: https://arrow.tudublin.ie/engscheceart

Part of the Electrical and Computer Engineering Commons

\section{Recommended Citation}

Bao, X. \& Ammann, M. (2008) Dual-frequency dual-sense circularly-polarized slot antenna fed by microstrip line. IEEE Transactions on Antennas and Propagation, 2008, vol.56, no. 3, pp.645-649. doi:10.1109/TAP.2008.9169

This Article is brought to you for free and open access by the School of Electrical and Electronic Engineering at ARROW@TU Dublin. It has been accepted for inclusion in Articles by an authorized administrator of ARROW@TU Dublin. For more information, please contact arrow.admin@tudublin.ie, aisling.coyne@tudublin.ie, gerard.connolly@tudublin.ie.

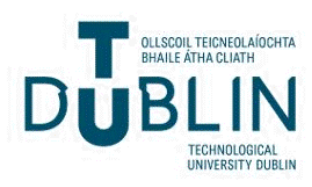




\title{
Dual-Frequency Dual-Sense Circularly-Polarized Slot Antenna Fed by Microstrip Line
}

\author{
Xiulong Bao and M. J. Ammann, Member, IEEE
}

\begin{abstract}
A new design of a dual-frequency dual circularly-polarized slot antenna is presented. The dual-frequency is achieved using a single-layer microstrip-fed configuration coupled to a modified annular-slot antenna. The dual sense circular-polarization is obtained by four unequal linear slots which augment the annular slot. Experimental results show the proposed antenna has good circular polarization characteristics for both right-hand circular polarization (RHCP) and left-hand circular polarization (LHCP). The $10 \mathrm{~dB}$ return loss impedance bandwidths for the lower (RHCP) and higher (LHCP) bands are $26.7 \%$ and $11.3 \%$, respectively. The $3 \mathrm{~dB}$ axial-ratio bandwidths are $6.1 \%$ and $6.0 \%$ with respect to $1.5 \mathrm{GHz}$ (RHCP) and $2.6 \mathrm{GHz}$ (LHCP), respectively.
\end{abstract}

Index Terms-Dual circularly polarization, dual frequency, right-hand circular polarization (RHCP)/left-hand circular polarization (LHCP), slot antennas.

\section{INTRODUCTION}

I $\mathrm{N}$ THE recent decade, slot antennas have again become the subject of great interest to the engineering designer due to their miniaturization potential and relatively wide bandwidth. Several slot antennas are reported to achieve improved performances, particularly for broadband and circular-polarization applications. In [1], a typical circular-ring slot antenna utilizing a stripline hybrid coupler feed-network achieves good broadband circular-polarization performance. In [2], a circularly-polarized square-ring slot antenna is proposed which is fed by a series microstrip-line coupled to two orthogonal sides of the square-ring slot to achieve circular polarization characteristics. An annularslot antenna array has recently been reported [3]. Various other slot combinations are reported to obtain compact/broadband circular polarization [4]-[7]. Annular slot antennas are also employed to obtain dual-frequency and multiple frequency operation by a shorted slot [8], or with a circular back-patch [9], or strip-line [10]. Recently, some techniques have been employed to provide dual circularly polarized antennas. In [11]-[14], a right-hand circular polarization (RHCP)/left-hand circular polarization (LHCP) antenna is achieved by PIN diode switching. In [15]-[17], dual circular-polarization is obtained by a feed network and two ports. A dual-frequency dual circularly-polarized patch antenna has been reported in [18], which consists of multilayer arrangement of two patches coupled to the feed points to

Manuscript received May 11, 2007; revised November 1, 2007. This work was supported by Science Foundation Ireland.

The authors are with the Centre for Telecommunications Value-chain Research, School of Electronic and Communications Engineering, Dublin Institute of Technology, Dublin 8, Ireland (e-mail: ammann@ieee.org).

Digital Object Identifier 10.1109/TAP.2008.916961

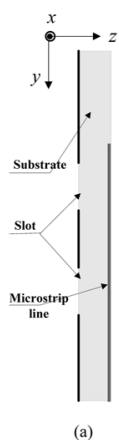

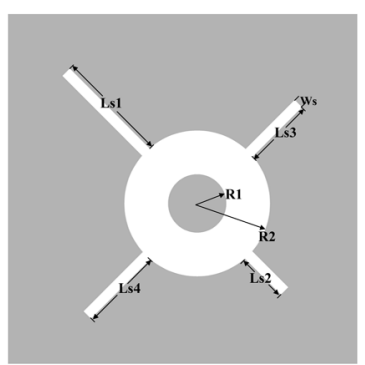

(b)

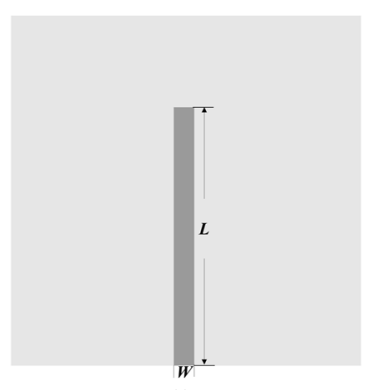

Fig. 1. Geometry of the dual-frequency dual circularly-polarized slot antenna. (a) Substrate, (b) slot, (c) microstrip line.

achieve dual circular-polarization. In comparison to this design, the proposed antenna is fabricated on a single layer and employs multiple slots.

In this paper, the single layer annular slot antenna is used to achieve dual-frequency and dual-sense circular-polarization by adjustment of the key antenna parameters, which are the inner and outer radii of annular-slot, the length of the four additional linear slots spurred from the annular slot and the length of microstrip feedline. The proposed antenna can provide broad impedance bandwidth and axial-ratio bandwidth. The right-hand $\mathrm{CP}$ and left-hand $\mathrm{CP}$ performance is realized simultaneously, for the first and second frequency, respectively. The proposed slot antenna can find useful application in indoor wireless communication systems and in satellite navigation systems.

\section{Design of Slot Antenna for Dual CIRCUlar POLARIZATION}

The geometry of the proposed slot antenna is illustrated in Fig. 1. It comprises an annular slot combined with four orthogonal linear slot arms. The annular-slot inner and outer radii are $R 1$ and $R 2$ respectively and the four linear slot arm lengths are $L 1, L 2, L 3$ and $L 4$ with the same slot width $W s$. The antenna is fabricated on an FR4 substrate, which has a relative permittivity of 4.2, a thickness of $1.52 \mathrm{~mm}$ and a loss tangent of 0.02 . The groundplane size is $80 \mathrm{~mm} \times 80 \mathrm{~mm}$. The width of microstrip line, which is centered on the substrate, is $w=3.0 \mathrm{~mm}$ for a $50 \mathrm{Ohm}$ impedance. The width $W s$ of the linear slot arms is $1 \mathrm{~mm}$. The slot arm width is selected for optimum bandwidth and matching. As this value is increased, the matching is lost, initially for the lower band $(W s=1.5 \mathrm{~mm})$. As $W s$ is reduced, the bandwidth of the high band is decreased. 


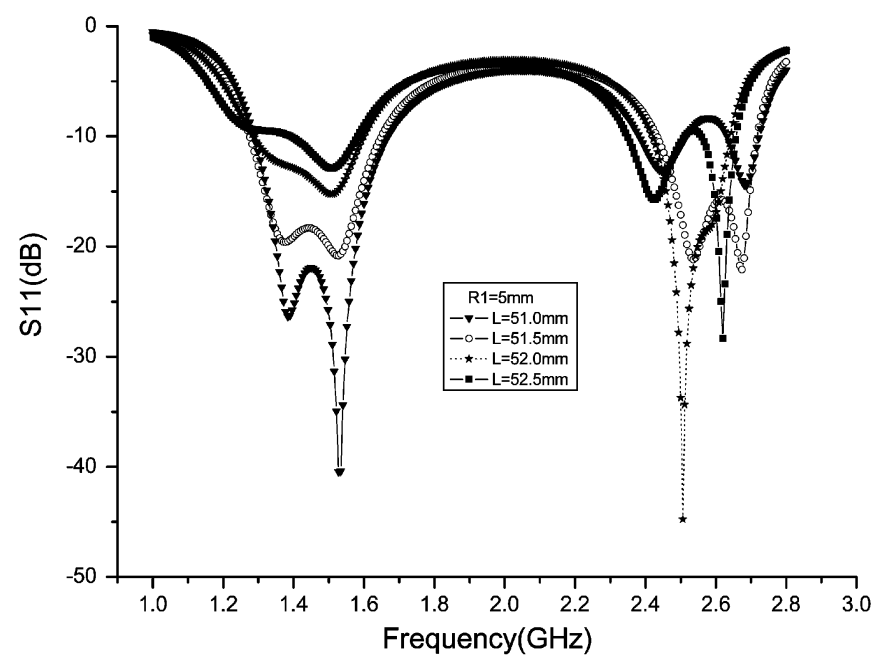

Fig. 2. Comparison of return loss for the proposed antenna for different feedline lengths.

For the conventional annular slot antenna, the resonant frequency may be approximated by:

$$
f=\frac{c_{0} \cdot K}{2 \cdot \pi \cdot \sqrt{\varepsilon_{e}}}, \quad K=\frac{2}{R 1+R 2}
$$

where $c_{0}$ is velocity of light and $\varepsilon_{e}$ is the effective dielectric constant of the substrate considering the annular and linear slots, which is relative to the slot guided wavelength, given in [1]. In the annular-slot, the introduction of the slot arms can be used to reduce the resonant frequency, and at the same time, provide a low and high frequency mode. They are also used to improve matching and are geometrically arranged to provide the necessary phase perturbation for circular-polarization. By adjusting the slot lengths, dual frequency operation is achieved by coupling a microstrip feedline to the annular-slot. The four unequal narrow slots are located at angles of $45^{\circ}, 135^{\circ}, 225^{\circ}, 315^{\circ}$ with respect to the feedline, which provide the necessary perturbation for circular polarization and degenerate the resonant modes into two frequencies. The lower resonant frequency is determined by the annular-slot dimensions and the length of the longest slot arm Ls1. According to the low frequency E-field distribution shown in Fig. 4(a), it can be seen that strong orthogonal fields are excited. One of the orthogonal linearly-polarized fields is produced in the annular-slot and linear slot Ls1, while the other field is realized in the annular slot and linear slots Ls3 and Ls4. By adjusting the length of Ls4 and Ls3, fields of nearly equal magnitude and with a phase difference of 90 degrees are realized, yielding circularly-polarized characteristics. In this case, for best axial-ratio and matching, the required difference in length between Ls1 and Ls4 is approximately one eight of the low frequency guide wavelength. The sense of polarization can be seen by looking at the phase sequence in Fig. 4(a). If $\mathrm{Ls} 1>\mathrm{Ls} 4$, then RHCP is obtained in the positive $\mathrm{z}$ direction.

In the same way, the resonant frequency of the high frequency mode is determined by the annular slot dimensions in combination with the length of shortest slot arm Ls2. As can be seen in the E-field distribution for the higher frequency in Fig. 4(b),

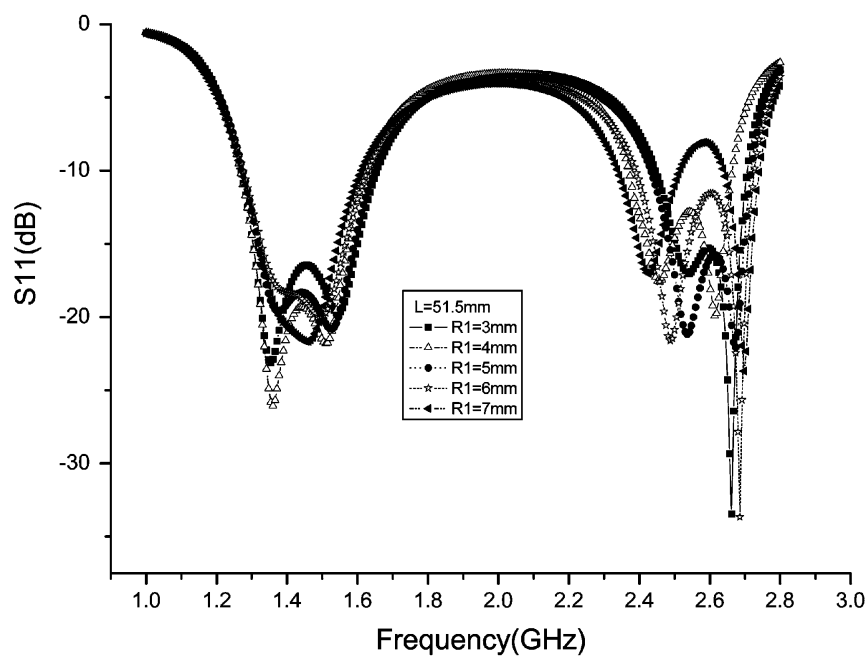

Fig. 3. Comparison of the return loss for the proposed antenna for different values of inner radius $(R 1)$.

one of the linear-polarized fields is excited in the annular slot and linear slot Ls2, while the orthogonal field is realized in the linear slots Ls3 and Ls4. By adjusting the length of Ls3 and Ls4, orthogonal fields of nearly equal magnitudes and of 90 degree phase difference are produced, hence circularly polarized characteristics. In this case also, there is about one eight of a guide wavelength (for higher frequency) difference in the length's of Ls3 and Ls2 for best axial ratio and matching. For Ls3 > Ls2, then LHCP is obtained in the positive $\mathrm{z}$ direction. So, two independent circular-polarization senses can be realized simultaneously by adjusting the four lengths of the narrow linear slot arms. In order to provide best matching and optimum performance, a parametric study was made using a numerical solver based on these initial dimensions of antenna.

\section{NUMERICAL ANALYSIS FOR THE DUAL-SENSE CIRCULARLY-POLARIZED SLOT ANTENNA}

A parametric study of the proposed slot antenna was carried out in order to achieve broadband dual frequency operation and dual circular-polarization. To decrease the complexity of the design, the following antenna parameters are selected as: $R 2=11.5 \mathrm{~mm}, L s 1=34.5 \mathrm{~mm}, L s 2=12.5 \mathrm{~mm}$, $L s 3=18.5 \mathrm{~mm}, L s 4=21.5 \mathrm{~mm}, W s=1.0 \mathrm{~mm}$.

Simulations are carried out using CST MWS based on the finite integration time-domain technique and an investigation of the antenna parameter dependence is made. The length of feedline $L$ and inner radius $R 1$ of circular patch are initially examined.

\section{A. The Effects of Variation of the Length of Microstrip Line L}

As the length of microstrip line $L$ is varied, the coupling to the annular-ring slot is altered and the antenna performance is also varied. The return loss dependence on this parameter is shown in Fig. 2. It is observed that the matching of the dual-frequency slot antenna is very sensitive to this parameter. Thus, the length of microstrip line $L$ needs to be optimized to provide circular polarization with good dual-frequency matching. In this paper, 


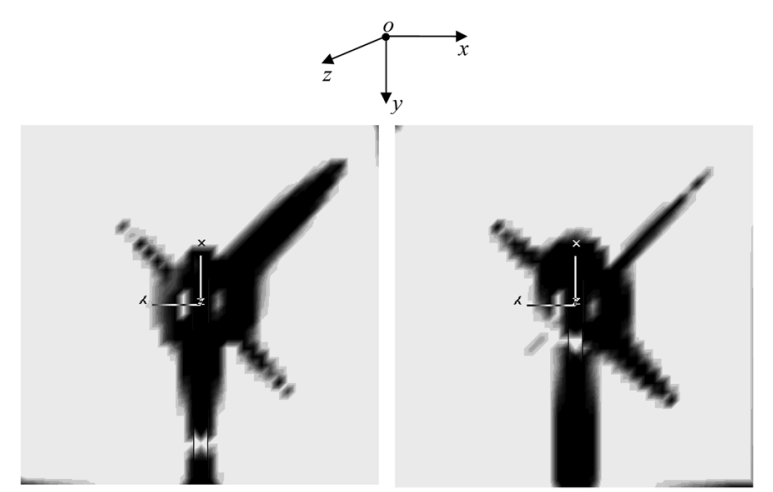

(1) 0 degree

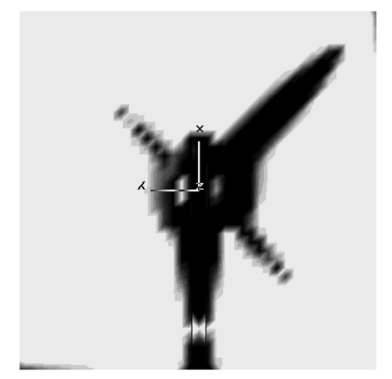

(3) 180 degree

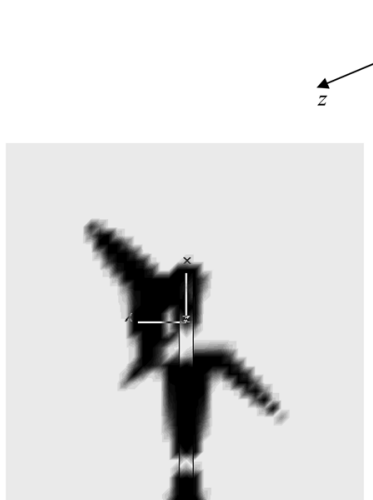

(1) 0 degree

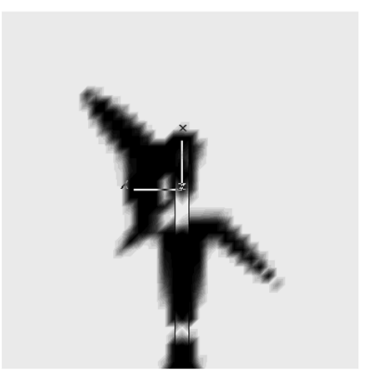

(3) 180 degree

(b)

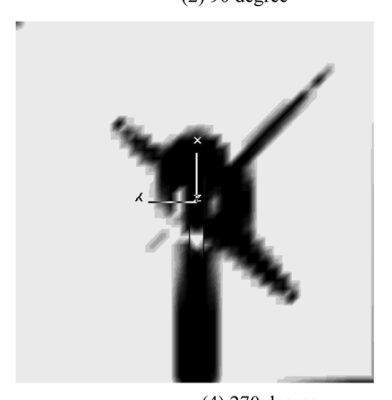

(a)
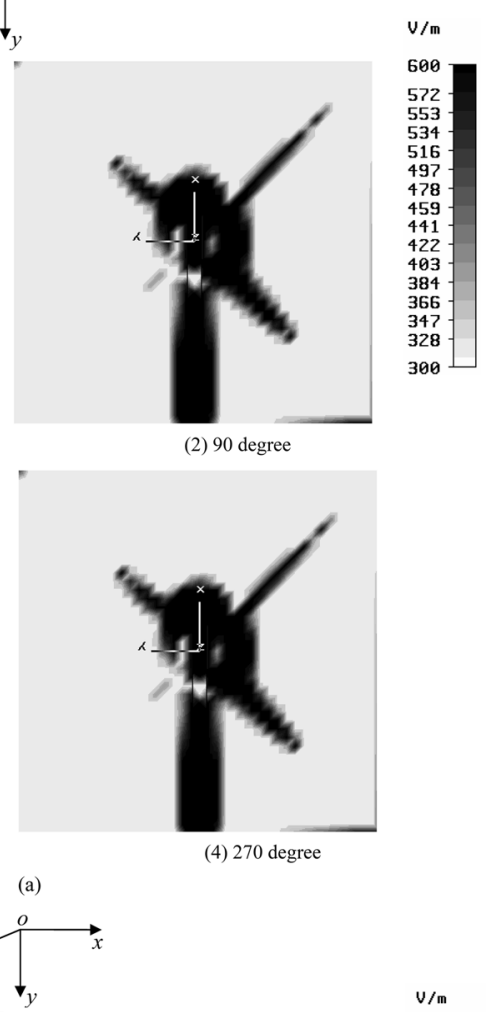

Fig. 4. The distributions and phase of the simulated electric field at (a) $1.5 \mathrm{GHz}$ and (b) $2.6 \mathrm{GHz}$. (1) 0 degree, (2) 90 degree, (c) 180 degree, (d) 270 degree.

the value of this parameter for the proposed antenna is selected as $L=51.5 \mathrm{~mm}$.

\section{B. The Effects of Variation of the Inner Radius of Annular-Slot R1}

Fig. 3 illustrates the return loss plots of the dual-frequency antenna for different values of annular slot inner radius $R 1$. It is clearly seen that the upper frequency shows heavy dependence

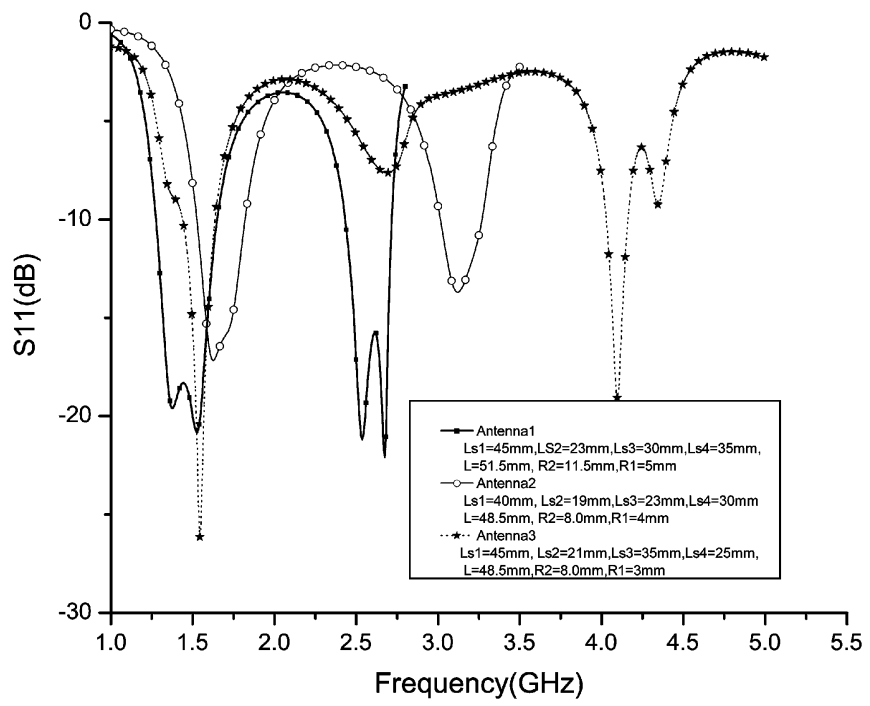

Fig. 5. Antenna parameters for frequency ratios of 1.75:1, 1.91:1 and 2.65:1.

on this parameter. The matching at this frequency is therefore realized by appropriate choice of inner radius $R 1$ and feedline length $L$, whereas matching at the lower frequency is determined mainly by feedline length. The appropriate $R 1$ size is selected as $5 \mathrm{~mm}$.

The distributions of electric field are simulated by using CST MWS and are shown in Fig. 4(a) for the lower frequency of $1.50 \mathrm{GHz}$ and Fig. 4(b) for the upper frequency of $2.60 \mathrm{GHz}$. It can be seen in this figure that fields exist on the edge of longer slot arms for lower frequency, whereas on the other hand, the distributions of electric field on the edges of short slot arms are strong at the high frequency. The frequency ratio is $1.75: 1$. By tuning the length of the slot arms, the change in frequency ratio of the two circularly-polarized operating frequencies can only be changed by about $5 \%$, because the matching degrades. The annular slot dimensions as well as the length of microstrip line need to be changed to achieve a broader range of frequency ratios, typically in the range $1.7: 1$ to $2.7: 1$. The parameter values and S11 response for frequency ratios of 1.75:1 $(2.674 \mathrm{GHz} / 1.528 \mathrm{GHz}), 1.91: 1(3.117 \mathrm{GHz} / 1.625 \mathrm{GHz})$ and 2.65:1 (4.095 GHz/1.545 GHz) are shown in Fig. 5.

\section{MEASURED RESULTS}

According to the results of the numerical analysis, the optimized parameters of the proposed slot antenna dimensions are as follows: $R 2=11.5 \mathrm{~mm}, L s 1=34.5 \mathrm{~mm}, L s 2=12.5 \mathrm{~mm}$, $L s 3=18.5 \mathrm{~mm}, L s 4=21.5 \mathrm{~mm}, R 1=5 \mathrm{~mm}, L=51.5 \mathrm{~mm}$, $\mathrm{W} s=1.0 \mathrm{~mm}$. The measured and simulated $S 11$ are shown in Fig. 6. The measured results are in good agreement with simulation. The measured results show the (10 dB return loss) input impedance bandwidth for the lower frequency (RHCP) is about $389 \mathrm{MHz}$ from 1.265 to $1.654 \mathrm{GHz}$, representing $26.7 \%$ with respect to $1.46 \mathrm{GHz}$, and the bandwidth of the higher frequency (LHCP) is about $292 \mathrm{MHz}$ from 2.446 to $2.738 \mathrm{GHz}$, representing $11.3 \%$ with respect to $2.59 \mathrm{GHz}$. Fig. 7 illustrates a plot of the measured and simulated axial ratio against frequency. The measured $3 \mathrm{~dB}$ axial-ratio bandwidth for the low band is 


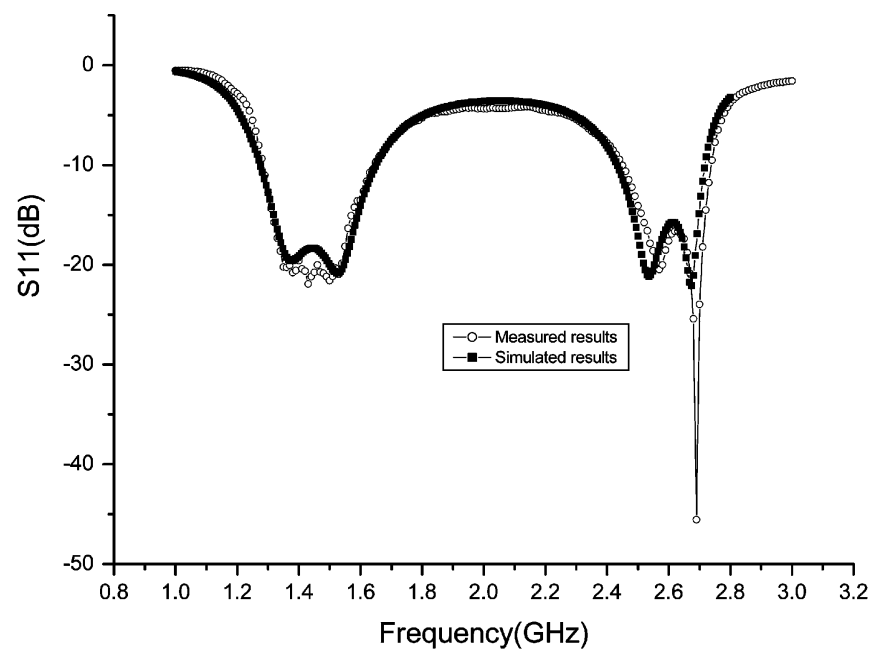

Fig. 6. The measured and simulated results of S11 for the proposed antenna.

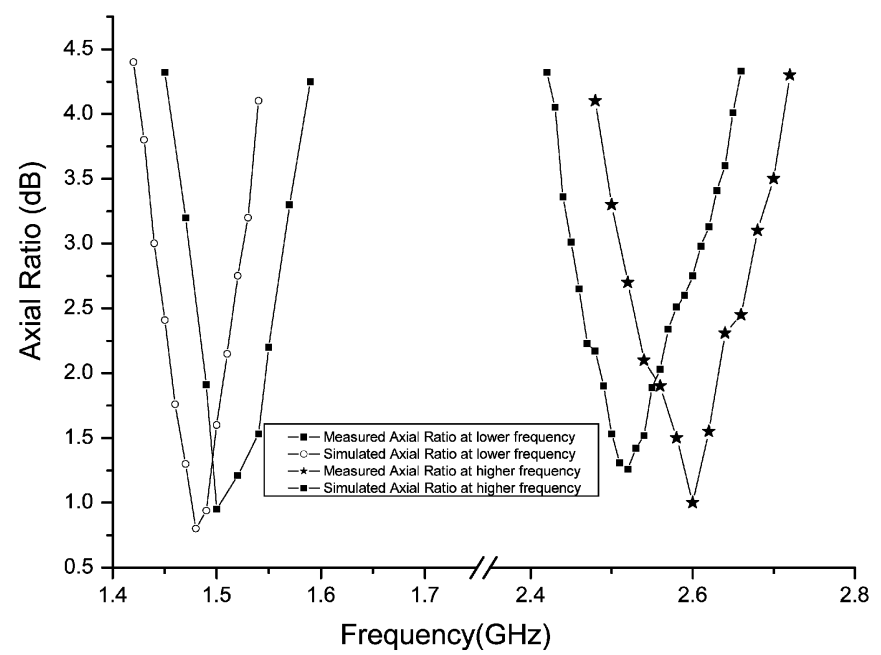

Fig. 7. The measured and simulated axial-ratio against frequencies for the proposed antenna.

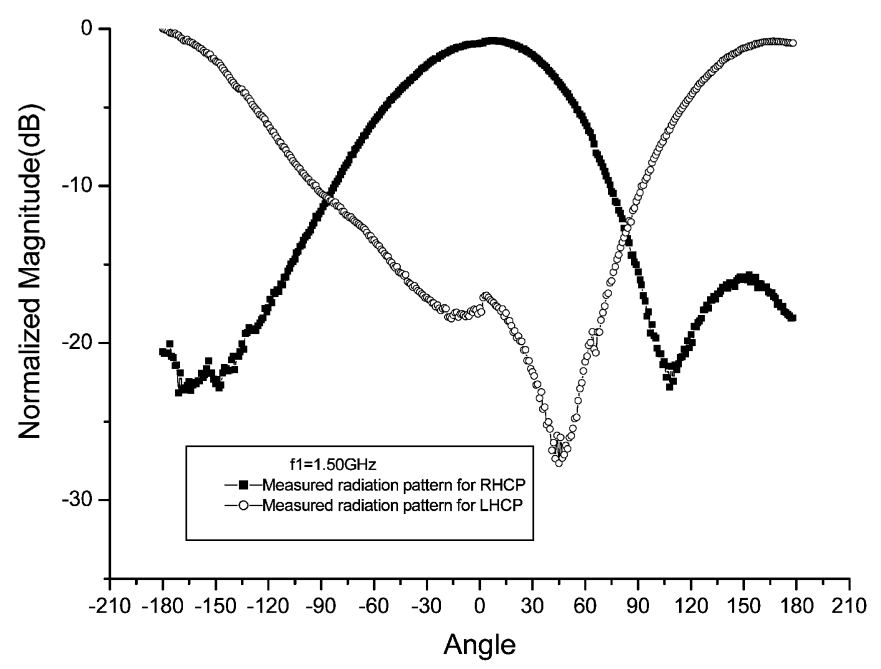

Fig. 8. Measured radiation patterns at $1.5 \mathrm{GHz}$ for the proposed antenna.

$92 \mathrm{MHz}$, from 1.474 to $1.566 \mathrm{GHz}$ for RHCP, corresponding to about $6.1 \%$ with respect to $1.5 \mathrm{GHz}$, and the measured axialratio bandwidth for the high band is $155 \mathrm{MHz}$, from 2.512 to

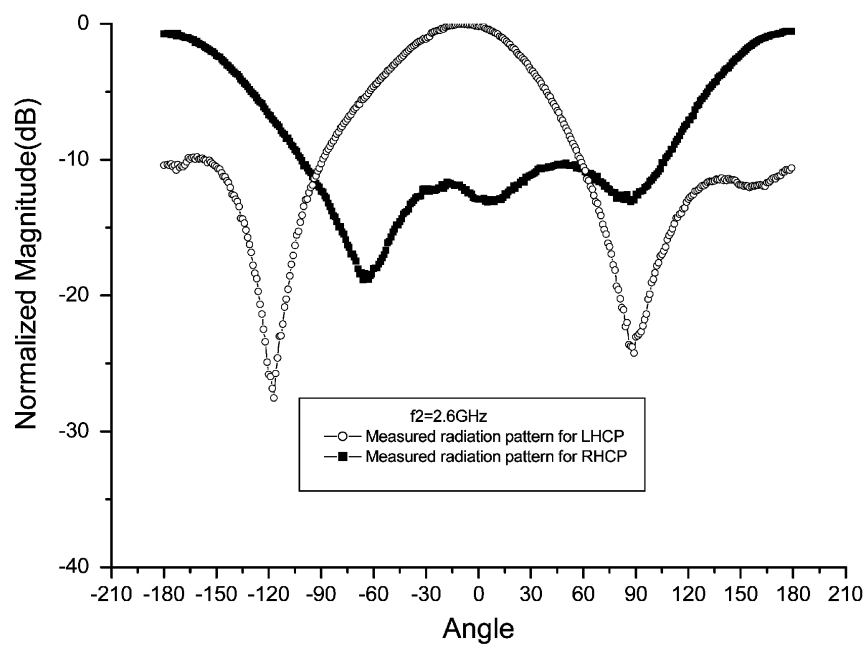

Fig. 9. Measured radiation patterns at $2.6 \mathrm{GHz}$ for the proposed antenna.

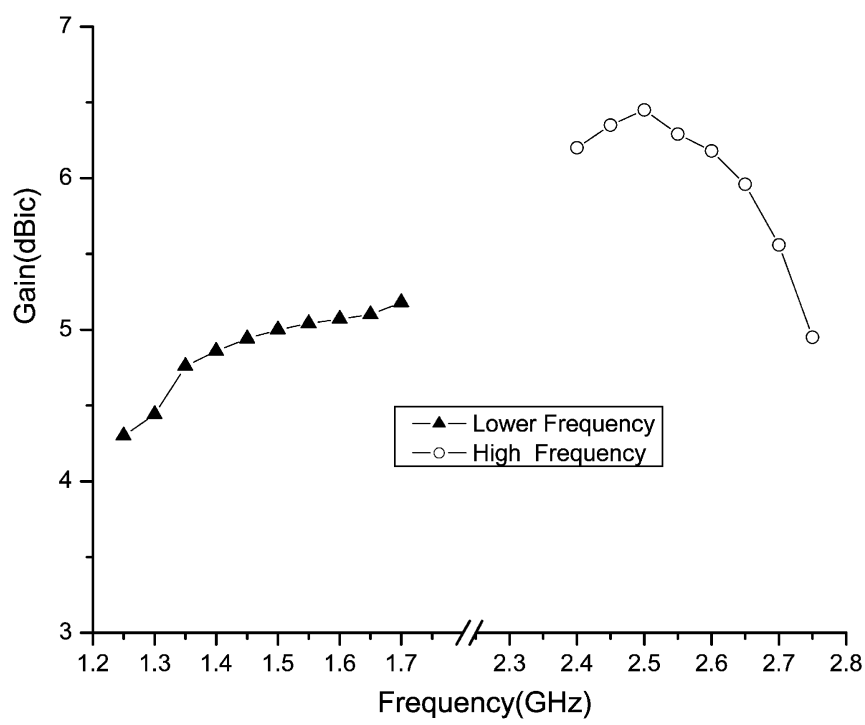

Fig. 10. The measured peak gain variation with frequency.

2.677 GHz for LHCP, corresponding to about $6.0 \%$ with respect to $2.6 \mathrm{GHz}$.

The measured RHCP and LHCP radiation patterns are measured and are illustrated in Figs. 8 and 9 for frequencies of 1.5 and $2.6 \mathrm{GHz}$, respectively. The cross polarization is better that 17 and $12 \mathrm{~dB}$ for the low and high frequency respectively. The peak measured gains of for the low and high frequencies are 5.2 and $6.3 \mathrm{dBic}$, respectively, as seen in Fig. 10.

\section{CONCLUSION}

A novel dual-frequency dual-circular polarization slot antenna fabricated on a single layer is examined. The proposed antenna can provide wide impedance bandwidths of $26.7 \%$ for first band and $11.3 \%$ for second band, respectively. The axial-ratio bandwidths achieved are greater than $6 \%$ for RHCP and LHCP, respectively. The proposed antenna can be applied to multiband multipolarized systems to mitigate interference effects. 


\section{REFERENCES}

[1] X. M. Qing and Y. W. M. Chia, "Circularly polarised circular ring slot antenna fed by stripline hybrid coupler," Elect. Lett., vol. 35, no. 25, pp. 2154-2155, Dec. 9th, 1999.

[2] J. S. Row, "The design of a square-ring slot antenna for circular polarization," IEEE Trans. Antennas Propag., vol. 53, no. 6, pp. 1967-1972, Jun. 2005.

[3] J. S. Row, C. Y. D. Sim, and K.-W. Lin, "Broadband printed ringslot array with circular polarization," Elect. Lett., vol. 41, no. 3, pp. 110-112, Feb. 3rd, 2005.

[4] S. K. Sharma, L. Shafa, and N. Jacob, "Investigation of wide-band microstrip slot antenna," IEEE Trans. Antennas Propag., vol. 52, no. 3, pp. 865-872, Mar. 2004.

[5] Y. Liu, Z. Shen, and C. L. Law, "A compact dual-band cavity-backed slot antenna," IEEE Antennas Wireless Propag. Lett., vol. 5, pp. 4-6, 2006.

[6] S. Y. Chen and P. Hsu, "Broad-band radial slot antenna fed by coplanar waveguide for dual-frequency operation," IEEE Trans. Antennas Propag., vol. 53, no. 11, pp. 3448-3452, Nov. 2005.

[7] H. A. Ghali and T. A. Moselhy, "Broad-band and circularly polarized space-filling-based slot antennas," IEEE Trans. Microw. Theory Tech., vol. 53, no. 6, pp. 1946-1950, Jun. 2005.

[8] J. S. Chen and H. D. Chen, "Dual-band characteristics of annular-ring slot antenna with circular back-patch," Elect. Lett., vol. 39, no. 6, pp. 487-488, Mar. 20th, 2003.

[9] H. Tehrani and K. Chang, "Multifrequency operation of microstrip-fed slot-ring antennas on thin low-dielectric permittivity substrates," IEEE Trans. Antennas Propag., vol. 50, no. 9, pp. 1299-1308, Sept. 2002.

[10] S. Nikolaou, G. E. Ponchak, J. Papapolymerou, and M. M. Tentzeris, "Shorted annular slot antenna (ASA) matched at three different frequencies," in IEEE AP-S Int. Symp. and USNC/URSI National Radio Science Meeting, 2005, vol. 1B, pp. 541-544.

[11] F. Yang and Y. Rahmat-Samii, "A reconfigurable patch antenna using switchable slots for circular polarization diversity," IEEE Microw. Wireless Compon. Lett., vol. 12, no. 3, pp. 96-98, Mar. 2002.

[12] N. B. Jin, F. Yang, and Y. Rahmat-Samii, "A novel patch antenna with switchable slot (PASS): Dual-frequency operation with reversed circular polarizations," IEEE Trans. Antennas Propag., vol. 54, no. 3, pp. 1031-1034, Mar. 2006.

[13] M. Fries, "Planar Antennas for Integrated Front-Ends," Ph.D. dissertation, Swiss Federal Institute of Technology, Zurich, Switzerland, 2004.

[14] M. H. Ho, M. T. Wu, C. G. Hsu, and J. Y. Sze, "An RHCP/LHCP switchable slotline-fed slot-ring antenna," Microw. Opt. Technol. Lett., vol. 46, no. 1, pp. 30-33, Jul. 5, 2005.

[15] W. J. Tseng and S. J. Chung, "A dual CP slot antenna using a modified Wilkinson power divider configuration," IEEE Microw. Wave Lett., vol. 8, no. 5, pp. 205-207, 1998.

[16] A. E. Fathy et al., "A novel planar polarized feed network/for dual circular polarization," in Proc. IEEE AP-S Int. Symp. and USNC/URSI National Radio Science Meeting, 2001, vol. 1, pp. 412-415.

[17] F. Ferrero, C. Luxey, G. Jacquemod, and R. Staraj, "Dual-band circularly polarized microstrip antenna for satellite applications," IEEE Antennas Wireless Propag. Lett., vol. 4, pp. 13-15, 2005.
[18] R. Shavit, Y. Israeli, L. Pazin, and Y. Leviatan, "Dual frequency circularly polarised microstrip antenna," Proc. Inst. Elect. Eng. Microw. Antennas Propag., vol. 152, no. 4, pp. 267-272, Aug. 2005.

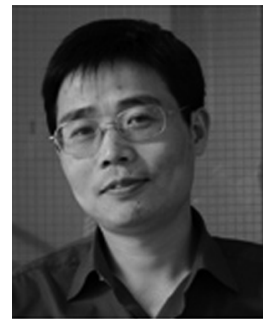

Xiulong Bao received the B.Sc. degree in physics from the Huaibei Coal Industry Teachers' College, Anhui Province, China, in 1991, and the M.Sc. degree in physics and the Ph.D. degree in electromagnetic and microwave theory from Southeast University, Jiangsu Province, China, in 1996 and 2003, respectively.

After graduating, he was a Postdoctoral Researcher at Shanghai Jiaotong University, Shanghai, before going to Ireland in 2004 . He is currently a Lead Researcher in the Centre for Telecommunications Value-chain Research (CTVR) Antenna Group, School of Electronic and Communications Engineering, Dublin Institute of Technology, Ireland. His main research interests include analysis and design of circularly polarized antennas, ultrawideband (UWB) antennas and multiband antennas. He has considerable skills in the miniaturization of antennas and the use of metamaterial/EBG structures to enhance antenna parameters, such as gain and axial-ratio bandwidth. $\mathrm{He}$ is also active in electromagnetic scattering and electromagnetic numerical computation (such as FDTD, PSTD, FDFD and MOM methods).

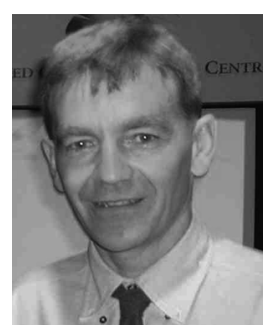

M. J. Ammann (M'96) received the Ph.D. degree in microwave antenna design from Trinity College, University of Dublin, Ireland.

$\mathrm{He}$ has eight years of industrial experience in radio systems engineering and antenna design with TCL/Philips Radio Communications Systems, Finglas, Dublin. He joined the School of Electronic and Communications Engineering, Dublin Institute of Technology, as a Lecturer in 1986 and was promoted to Senior Lecturer in 2003. He is the Director of the Antenna and High Frequency Research Group, currently comprising 12 members and also leads the antenna research within Ireland's Centre for Telecommunications Value-chain Research (CTVR). His research interests include electromagnetic theory, antenna miniaturization for terminal and ultrawideband applications, microstrip antennas, metamaterials, SAR evaluation, antennas for medical devices and the integration of antennas with photovoltaic systems. He has in excess of 100 peer-reviewed papers published in journals and international conferences.

Dr. Ammann became a Chartered Engineer and member of the Institution of Engineering and Technology (IET, formerly known as the IEE), London, U.K., in 1986. He is a member of the IEEE International Committee for Electromagnetic Safety and participated in the revision of the IEEE Std C95.1, 2005 standard for Safety Levels with Respect to Human Exposure to Radio Frequency Electromagnetic Fields, $3 \mathrm{kHz}$ to $300 \mathrm{GHz}$. He is also a member of Communications and URSI Radio Science Committee of the Royal Irish Academy. He co-Chaired the Special Session on Antennas for UWB Wireless Communication Systems, IEEE APS, Columbus, Ohio, 2003 and was Track Chair for Antennas and Propagation for the 65th IEEE VTC, Dublin, Ireland, 2007. 